\title{
Internal and External Rehabilitation Process of East Java Drugs Therapy Houses in Therapeutic Communication for Drugs Addicts
}

\author{
Sanhari Prawiradiredja ${ }^{1}$, Iwan Joko Prasetyo ${ }^{2}$, R. Ayu Erni Jusnita ${ }^{3}$ \\ \{sanhari.prawiradiredja@unitomo.ac.id¹, iwan.joko@unitomo.ac.id², rayu@unitomo.ac.id ${ }^{3}$ \} \\ Universitas Dr. Soetomo Surabaya, Indonesia ${ }^{1,2,3}$
}

\begin{abstract}
The institution that handles social rehabilitation of drug addicts is called Mandatory Recipient Institution (IPWL-Institusi Penerima Wajib Lapor). There are two main processes that take place in rehabilitation house, namely the internal processes carried out in the form of quarantine and external process. This study seeks to discover the communication patterns applied in therapy houses. In internal processes there are forms of habituation in working groups such as in the family so that they learn to carry out basic social functions in interactions that are neglected and damaged while becoming addicts. If the process is successful, they will be in a clean condition from drugs or in abstinence condition. The external process occurs after the abstinence condition of the addicts. The family and social environment chosen is an important factor in the addict's life. Basically, there are two therapeutic communication process that occur namely interpersonal communication and group communication. Both play important and unique roles in internal or external process in social rehabilitation of drug addicts. Counselors, family members, friends and peers play important roles in this process. The important thing in therapy is expressed through understanding, empathy, respect, attentive, availability, genuinely, support, equality, self-disclosure, openness. Aspects that support therapeutic communication include nonjudgmental situation, promoting equality, smart interpretation of specific communication context and creating appropriate and feasible situations.
\end{abstract}

Keywords: IPWL-Therapy House, Therapeutic Communication, Counselor, Drug Addict.

\section{Introduction}

Mandatory Recipient Institution (IPWL-Institusi Penerima Wajib Lapor) is institution that handles social rehabilitation of drug addicts based on social-community initiatives. To survive and carry out its role successfully, IPWL as mandatory recipient institution must maintain its rehabilitation process effectively and functionally. With the new regulation from the government, which requires drug users to be socially rehabilitated, the role of IPWL as a therapy home is becoming increasingly important. Indonesiainside.id reported that 19.000 narcotic addicts in Indonesia were rehabilitated in 179 IPWL all around 33 provinces in Indonesia. This data described that IPWL has a large role in handling the problem of drug abuse in Indonesia. IPWL is a medical and social rehabilitation institution aimed to rehabilitate drug addicts. This institution was formed by the government based on the Decree 
of the Minister of Health RI No. 18/Menkes/SK/VII/2012, with the aim to provide assistance, treatment, and medical or social rehabilitation for narcotics addicts. BNNP (National Narcotics Council) East Java Province informed that the majority of drug addicts are among adolescents of productive age and they are involved in the problem of drug abuse due to mistakes in social relationships and broken home family backgrounds. The state has an obligation to facilitate the rehabilitation activities by establishing several designated therapy houses (IPWL). With funding from the government, the therapy home provides free medical services to those who, with their own awareness, want to come to the IPWL to report themselves as drug users who want to stop their dependence on drugs.

The problems faced by IPWL in social rehabilitation are certainly not easy because the clients faced are individuals who have problems with their social behavior due to previous drug use. The tendency that arises is the behavior of those who are socially inappropriate, improper, difficult to adjust socially and even have committed criminal acts. Two basic problems faced by former drug addicts are setback or disruption in social relations and health problems involving physical fitness and pain due to stopping using drugs. This problem becomes the main social context in handling therapeutic communication for narcotics addicts. The counselors will be very concerned about the process of social interaction in therapeutic communication carried out because it will affect the effectiveness of therapeutic results. And this will be a problem in the dynamics of internal processes in the therapy home because those who deal with therapeutic communication problems have different backgrounds, namely counselors with a therapeutic background, social workers or social volunteers. Therefore, management of workers becomes the main issue besides the issue of routine funding and the provision of representative rehabilitation facilities. Of course, the main problem is how to manage therapeutic communication in the in-house process and after care process after the drug users stop using drugs. The condition of relapse or drug reuse has always been the main problem of former drug users.

\section{Research Method}

This study uses qualitative methods to explore, describe and understand meaning derived from social or humanistic problems by asking questions, collecting data, analyzing data inductively, and interpreting meaning from the interview and observations [1]. Data collection techniques, 1) Observation is done by reviewing to the field research to observe the behavior and activities of individuals at the study site. 2) Interviews are carried out with face to face interviews (direct interviews) with participants with questions that are generally unstructured and open nature. 3) Qualitative documents in the form of reports or books published by therapy houses. The data obtained is then clustered and created in typological units which can eventually be interpreted.

This study seeks to discover the process of communication patterns applied in therapy houses that can be either personal or group therapy. Dziopa and Ahern identified a typology of nine general attributes which have practical implications for psychiatric /mental health nursing education and practice, namely (a) conveying understanding and empathy, (b) accepting individuality, (c) providing support, (d) being there/being available, (e) being genuine, (f) promoting equality, (g) demonstrating respect, (h) maintaining clear boundaries, (i) having self-awareness [2]. Meanwhile, there are basically four therapeutic models that can be applied 
(a) CBT: Cognitive Behavioral Therapy,(b) DBT: Dialectical Behavior Therapy, (c) ACT: Acceptance and Commitment Therapy [3] and also (d) GAT: Group Activity Therapy [4].

\section{Result and Discussion}

The main therapeutic communication application for drug addicts is the residential care phase. In this phase, all forms of therapeutic communication are carried out. The initial process begins with the assessment. Drug addicts enter the therapy home through their own awareness, family intervention, social community or active police action. The first stage carried out by the home therapy is physical and psychological checking of the client due to drug use. If it is physically not possible for clients to carry out psychological social therapy, then what is done is medical treatment first. If this physical problem has been resolved, the counselor will draw up a treatment plan for the addicts. The first dynamic that arises is about the capacity of the therapy home and how many addicts are handled in the therapy process.

The basic concept of handling home drug therapy is social therapy. Being influenced by narcotics, the client's behavior is usually socially improper, difficult to adjust, lacks discipline and even has a history of crime due to his dependence on drugs. This residential process will run effectively because it takes place in a quarantine atmosphere for three months. Clients will be directed to rearrange their lives in understanding their status and roles, carrying out social functions, goup disclosure and increasing individual and social competence. This process is carried out in a daily cycle starting to wake up in the morning until bedtime at night. There are several components carried out in residential care: (a). Treatment plan, (b). Material session, (c). Counseling individuals or groups, (d). Medical referral, (e). Psychologist support, (f). Sports and recreational outings, (g). Vocational training, (h). Continuous care program, (i). Religious support, (j). 12 step involvement [5]. The basis of therapy is group activity therapy. All therapy programs are packaged to support the process of abstinence of addicts. If a violation or deviation is committed by the addict then the initial treatment is carried out as a group as their affiliative responsibility. Therefore, the term for their togetherness is 'family'. And if they put themselves in the process of communication, they start by saying the name and accompanied by the title "I'm an addict". Expressions like this are made to show that they are facing a problem that must be resolved socially with their families. If specific treatment is needed, therapeutic interpersonal communication can be arranging to solve the client problem. The interpersonal therapeutic communication process can also be carried out if addicts experience problems that are personal and must be dealt with specifically and deeply. Urine tests are always done to check and preventively maintain the abstinence process.

Handling as a group in the management of the division is done if addicts are treated in large numbers and meet the capacity of the therapy home. The existence of this departments depends on the interests and needs of the institution. T. Departmental membership can be in: (a) Kitchen department, (b) Landscape department, (c) Housekeeping and maintenance department, (d) Expeditor department, (e) Mental spiritual department, (f) Gastronomes department.

There are several joint activities inside the community create by rehabilitation institution. Counselors participate in this activity as organizer, facilitator and counselor. They called the activity as sessions. This session is different for each institution which are applied uniquely and varies based on the capacity, needs and specifications of the therapy home. These sessions are usually seen in observation: (a) Wellness, wellness is sport activity in the morning to 
improve the fitness and enthusiasm of the client as a member of the community. Expression of joy in the form of body movements and verbal messages are expected to appear in this activity. The role of counselor is to grow and stimulate the existing situation. Of course, appropriateness is something important to consider because it is part of good social behavior, (b). Functions, activity of clients to clean the environment and homes in institution. In general, what is cleaned up is the environment around the dwelling which is a shared responsibility. Landscape department responsible in this activity. Room cleanliness, bed and kitchen are the responsivity of the kitchen and housekeeping department. Counselors with chief and crew of department evaluate the overall environment in morning general inspection (GI), (c). Morning Meeting, activity led by counselor to evaluate what happened the day before: What's the problem? And how to solve the problem. All members of community are allowed to participate. Members who were chosen on the previous night chose today's theme by providing specific description. In social rehabilitation institution based on religion, morning meeting start with praying and verse choice, (d). Seminar/Class, in seminar session, counselor gives education to clients in their competence. Topic of seminar can be various from character and category of drugs, psychological or personal improvement or religious matters. In this session, besides counselors who play a role in this session, sometimes they also invite outside speakers such as psychologists or religious leaders, (e). Confrontation, a session or forum create to remind each other or admonish each other for mistakes made by other community member. The process start with a client sees another client doing and act that make him feel uncomfortable and considers it wrong based on general ethic and understanding. The first thing he do is to confirm the action. If the accusation or reprimand is accepted, the confronted client will confirm the error and promise to correct his actions. There are institutions that require each client to make 5 confrontations for his friends who make mistakes. But there are also those who only confront only if there any errors made by his colleagues, (f). Clients Presentations, this session is a follow up session or continuation after another session. After vocational, psychoeducation, or religious class/session, clients have task that must be presented at the forum in front of class in the presence of friends. The counselor's duty is to stimulate the client to be assertive and want to practice and develop themselves, (g) Care and Concern, this session is improving by the counselor based on certain necessity. The counselor can state a problem relate with client's past experience. All clients can give opinion or statement about te topic, the solution, improvement etc. The problem raised can be anything. What matters is the problem is related to client's needs, (h). Drop Guild, sometimes clients need a forum to disclose his mistakes for several reasons. Maybe he needs comprehensive understanding and forgiveness from all member of community. He can use this session for this purpose. On the other hand, counselors can use this session to raise client mistake issues that need to be explain in general. The purpose of this session is for mutual understanding, the search of collective solutions and a sense of community togetherness, (i) House Meeting, this session is used to solve problems to be addressed together. There may be an interest in changing or refreshing the composition of the department. 'Case conference' is other terms used by other social rehabilitation institution, (j) Vocational Session, this session is used to improve the ability or client's skill to get opportunity to find job, to work and earn income. The resource person is an expert who masters the field of work. The field of work can vary, such as agriculture, livestock, trade, creative work and so on. Counselors usually consider the interests, talents and requests of clients. The names of these sessions do not apply equally to all rehabilitation houses. Some use general terms such as morning, afternoon or evening sessions. The main goal is functional therapy. There are aspect relates with socially cognitive, whose expectations are changes in social behavior. 
Counselors must always try to apply creativity, adaptation and variety of activities to maintain the sustainability of the program so that the abstinence of drug use in a conducive atmosphere. This is necessary because most of these addict therapy homes are run in home environments that are designed for residential use and not in the form of healing clinics. Likewise, counselors who serve addicts are social volunteers who were formerly addicts. Sometimes an unpleasant atmosphere arises, for example when they also have to do a urine test on a fellow counselor. The discomfort is also when counselors face addicts [6], they are individuals who because of drug use have (a) Physical problems, damage to the formation of nerves and other organ functions, certain diseases due to drug injection and so on, (b) Psychological problems, experience feelings of irritation and depression, insecurity, loss of self-confidence, feeling tense and anxious, (c) Social impact, the emergence of anti-social actions, anti-immorality, feelings of exclusion and social stigma from the social environment and loss of social relations. To deal with this situation the counselor is seeking a form of therapy that are expressed through understanding, empathy, respect, attentive, availability, genuinely, support, equality, self-disclosure, openness. They are also creating aspects that support therapeutic communication include nonjudgmental situation, promoting equality, smart interpretation of specific communication context and creating appropriate and feasible situations.

External dynamics arise in the aftercare program or half way house program that is implemented after the addict is outside the therapy house. Addicts who don't use drugs anymore have to face the reality of the outside world. They must be empowered to be independent and free from the possibility of relapse - using drugs again. The problem that arises here is (a)the lack of counselors to deal with external issues - after care programs. Funds covered by the social ministry are also not related to this external process, (b) fostering the skills of addicts so that they can have a productive business is not easy and is not cheap, (c) Access to funds for external activities can indeed be obtained from the social department or local government but the process takes time and sometimes the amount obtained is not as expected. (d) Continuation of routine meeting to strengthen psychological condition of addicts requires extra effort from counselors. The creativity of the home therapy manager is needed to overcome these difficulties.

\section{Conclusion}

The handling of therapeutic communication for drug addicts in Indonesia is something serious because Indonesia is in a drug emergency situation. The existence of home therapy is very instrumental in this process. Several dynamic factors need to be considered in dealing with the problems of therapeutic houses for drug addicts. First, the physical condition of the building where the therapy is still a building that is actually prepared for residential and not specific as a therapy house or healing clinic. Of course, these non-governmental organizations must continue to be appreciated by providing support especially from the government or perhaps philanthropic Maecenas who are willing to provide economic assistance.

An increasing number of counselors is of course also needed to deal with the increasing number of drug users who need to be rehabilitated. On the other hand, increasing their ability to conduct therapeutic communication must be increased continually. Complex residential internal handlers require measurable and effective abilities in dealing with the health and recovery of addicts. Typology issues handling addicts with their specific and unique problems 
require adequate therapeutic capacity from the counselor. Basically, the process of in-house therapy relies on group therapy activity, which interpersonal, cognitive and dialectical aspects of therapy are also included. Arrangements and oversight can be more easily done. The biggest problem arises in the external process, addicts are no longer in quarantine conditions that can be monitored easily and freely. Regular meetings in the Narcotics Anonymous format which are held can be hampered because of the awareness of addicts who lack motivation to attend the actual event to strengthen them psychologically and to deal with relapse situations. The number of counselors available to support this external program is also a constraint. The need for funding allocation to support their activities must be covered by the therapy house itself by implementing an independent fund management system with a substitution system. This is important because support group is invaluable clinical vehicle as stated by Fourie [7] "...The support group is usually the one place that individuals are understood, feelings can be validated and help can be received'. Therapeutic communication can grow in such communal situations. The communality itself can be grown by people who have competence and motivation.

\section{References}

[1] J. W. Creswell and J. D. Creswell, Research design: Qualitative, quantitative, and mixed methods approaches. Sage publications, 2017.

[2] F. Dziopa and K. J. Ahern, "What makes a quality therapeutic relationship in psychiatric/mental health nursing: A review of the research literature," Internet J. Adv. Nurs. Pract., vol. 10, no. 1, p. 7, 2009.

[3] P. L. Wachtel, Therapeutic communication: Knowing what to say when. Guilford Press, 2011.

[4] L. Zainun, Suwardi Lubis; Lubis, "The Use of Therapeutic Communication Symbol to Motivate Patient's Healing," IOSR J. Humanit. Soc. Sci., vol. 22, no. 7, 2017.

[5] R. A. E. Iwan Joko; Prawiradiredja, Sanhari; Jusnita, "Patterns of Therapeutic Communication in Rehabilitation Institution for the Narcotics Users in East Java, Indonesia, Ashidin Publishing," $J$. Drug Alcohol Res., vol. 8, 2019.

[6] W. T. Yolanda, "Rehabilitasi di Pusat Perawatan Pecandu Narkoba Ditinjau dari Komunikasi Terapeutik," J. Ilmu Komun., vol. 5, no. 1, pp. 13-27, 2014.

[7] R. J. Fourie, Therapeutic processes for communication disorders: A guide for clinicians and students. Psychology Press, 2010. 